\title{
A Network-Based Dynamic Analysis in an Equity Stock Market
}

\author{
Juan Eberhard, Jaime F. Lavin, and Alejandro Montecinos-Pearce \\ Escuela de Negocios, Universidad Adolfo Ibáñez, Santiago, Chile \\ Correspondence should be addressed to Alejandro Montecinos-Pearce; amontecinospascal@gmail.com
}

Received 27 July 2017; Revised 15 September 2017; Accepted 4 October 2017; Published 27 November 2017

Academic Editor: Thiago C. Silva

Copyright (C) 2017 Juan Eberhard et al. This is an open access article distributed under the Creative Commons Attribution License, which permits unrestricted use, distribution, and reproduction in any medium, provided the original work is properly cited.

\begin{abstract}
We study how changes in the structure of a brokers' transaction network affect the probability with which the returns and volume of the traded financial assets change significantly. We analyze how the dynamics of the brokers' transaction network are associated with the returns and volume observed in the Chilean stock market. To do this, we construct and validate an index that synthesizes the daily changes of the brokers' transaction network structure of equity market transactions. We find that the changes of this structure are significantly correlated with variables that describe the local and international economic-financial environments. In addition, changes in the brokers' transaction network structure are associated with a greater probability of positive shocks of more than two standard deviations in the stock exchange index return and total traded stock volume. These results suggest that the structure of the brokers' trading relations plays a role in determining the returns and volume of transactions in the Chilean stock market.
\end{abstract}

\section{Introduction}

Trading stocks, bonds, or currencies create a transaction network among brokers which stems from the architecture of the financial market, which in turn affects the formation of capital asset prices and returns. This network of brokers' transactions, in a broad sense, reflects both the investor-lender choices based on the information they both have and the brokers' information. The asset pricing literature usually assumes that the markets operate free of transaction costs and without any friction. The latter assumption is challenged both theoretically and empirically. First, from the market design perspective, a frictionless market implies ideal trading conditions [1]. Thus, changes in the network of transactions between brokers should not affect the returns and the volumes traded. However, from the financial market microstructure perspective, asset prices and return formation is a process governed by the rules that regulate and create the interactive mechanisms between investors (buyers), lender (sellers), and brokers in the market [2]. These rules also determine the existence and participation of brokers in the market. This occurs because these rules impose participation costs, funding constraints, and search costs that not only create imperfect competition but also may affect prices and returns through broker's trading behavior [3]. Second, the empirical evidence shows that there exist frictions in financial markets. Thus, changes in the brokers' transaction network can reflect frictions stemming from qualitatively significant changes in the heterogeneous information available to market agents for a given set of market rules and therefore affect capital assets pricing and returns. For example, during the financial crisis of 2008, the valuation of financial assets was affected by two distinct behaviors: liquidity hoarding, and its implied reduction on transactions, and flight to quality, that is, the flight from toxic assets toward risk-free assets [4]. Both behaviors not only affected the observed prices and returns, but also added further tension to the financial system and highlighted the difficulty of modeling how the information flows can change the structure and implications on the returns of the investor-lender financial network and the brokers' transaction network, henceforth the transaction network. This difficulty centers mainly on the fact that networks are multidimensional mathematical objects, whose structure cannot be completely described by a single dimension. That is, changes in broker's information and/or her financial conditions may lead to changes in each broker's decisions on how much to trade and who to trade with, thereby varying the direct and indirect trading relations between brokers or structure of the transaction network. Moreover, the multiple dimensions that characterize a network's topology may be interrelated, which, 
in the case of a financial network, can have nonlinear effects on the prices and returns of the traded assets as the literature has reported $[5,6]$.

The latter argument partially illustrates the complexity of the issue of modeling the effect of a transaction network structure on the risk and returns of capital assets. Additionally, when considering that the network structure varies over time, it is necessary to study how the changes of the network structure across time affect the equilibrium of financial markets. Thus, we study how changes in the brokers' transaction network structure affect the probability with which the return and volume of financial assets change significantly. Our approach is dynamic and emphasizes the analysis of the structural changes in the brokers' transaction network and their effects on the return and volume of a financial market. Given that variations in financial assets' returns affect the financial position of financial intermediaries, our research question is related to what the literature has called systemic risk. However, the study of systemic risk is not our focus; rather our aim is to shed some light on the effect of changes in the transaction network's structure on market dynamics and its implied returns and volume in the context of an equity market.

The literature that examines networks in financial markets has focused on the implications of three static properties of the networks and their relationship with the stability and fragility of financial systems. First, Kiyotaki and Moore [7], Allen and Gale [8], and Freixas and others [9] study the effect of financial system structure on systemic risk, developing the first formal contagion models in banking/financial networks. They find that, in the context of a banking system, more interconnected network architecture or topology increases the system's resilience to the insolvency of one particular bank, because the losses generated by an insolvent bank are absorbed by a larger number of actors in the network. Thus, a larger number of interconnections or links reduce the effect of negative shocks on the rest of the system.

However, and in contrast to the previous conclusion, Vivier-Lirimont [10] and Blume and others [11, 12] indicate that a network with a high interconnection density can act as a destabilizing force on the system, increasing the probability of systemic defaults while increasing the number of counterparts in a banking network. These apparently contradictory views illustrate the complex relation between the network structure and systemic risk. Acemoglu and others [6] and Haldane [4] show that the denser the interconnections are, the more stable the network will be in the event of small negative shocks. However, in the event of a larger shock on a key bank in the network or hub, the same interconnections propagate the shocks, increasing the fragility of the system due to the possibility of contagion. In other words, one characteristic of the network may generate more resilience under certain condition or threshold or may act as a source of systematic risk and instability ${ }^{1}$. A second aspect explored in the literature is how the distribution of interconnections affects the systemic reaction to shocks. When links are formed randomly, a Gaussian distribution of links with "fat middle and thin tail" is obtained $[13,14]$. However, a financial network characterized by a distribution of links with thin middle and long fat tail is more robust to random shocks but is weaker against specific shocks in the hub nodes, which can collapse the functioning of the entire network [15]. Finally, the third characteristic of studied financial networks is related to the degree of node separation-the "small world" property. For networks where there are certain agents playing a key role in the connectivity of the network or key nodes, local disturbances are more likely to have global effects on the network. Thus, one particular property of the network structure implies that a local problem may lead to a global one, increasing the systemic risk of the financial system [16].

These three static characteristics mentioned are studied by Haldane [4] in a sample of 18 developed and emerging countries for the period of 1985-2005. Haldane finds high levels of interconnection, long-tailed degree distributions, and small degrees of separation in the global financial network of this set of nations. Then, from the point of view of financial system stability, the global financial network of this sample may be understood as a robust-yet-fragile system. In this, systems under certain conditions, such as loss of confidence in certain key nodes, would favor a rapid transmission of global financial shocks.

Another implication derived from this robust-yet-fragile characteristic of financial networks is related to how other network structure characteristics, such as their centrality measures, may affect the systemic risk. However, no consensus has been reached regarding the measurement and estimation of the systemic risk of a financial network, and the traditional robustness measurements do not capture its fragility $100 \%[4]^{2}$. In an attempt to gain more accuracy in the estimation of systemic risk in banks, Guerra and others [17] propose novel systemic risk indicators that can measure the effect of one bankruptcy over the entire system.

An alternative approach is to study the parallelism between the analysis of the systemic risk in financial networks and electrical, ecological, or ecosystem networks. This makes it possible to apply analytical models and tools from these last fields to the analysis of financial markets. May and others [18] find that the impact of an external shock on the contagion rate in a network depends not only on the network topology but also on the feedback between the agents that comprise it. That is to say, a system's reaction to a shock depends not only on the current network structure but also on its evolution over time, and therefore it emphasizes the importance of studying the dynamic properties of the network topology. An advance in this direction is the work of Sensoy and Tabak [19] who apply a dynamic approach to analyze the time-varying dependence structure of a stock market.

It is worth noting that the financial agents' trading decisions are not solely determined by current information, but they follow a dynamic process of purchase and sale decisions that continuously give feedback on internal and external network information. For example, the investment and divestment decisions of money market intermediaries during the crisis of 2008 affected liquidity, interbank interest rates, and therefore fixed income, equity, and derivative instrument prices, among others. This behavior and its subsequent chain reaction are not captured by traditional risk analysis [20]. This occurs because static risk measures focus on estimating the 
risk of specific nodes not giving an overall risk assessment of the network and its feedback processes.

In summary, the evidence indicates that various structural dimensions of a network affect the characteristics of the equilibrium in financial markets. Moreover, these relations tend to be nonlinear and involve the interaction among several network structure characteristics. Additionally, the static network analysis must be complemented with dynamic measures that capture the evolution and complexity of the relationships between financial system actors or a subgroup of these. In this line of research, Haldane [4] proposes a complementarity between the development of dynamic measures of systemic risk and measures of idiosyncratic risk of the nodes. Aligned with Haldane's proposal and considering the empirical evidence that indicates that transaction costs and frictions in financial markets affect asset's values, returns, and volatility [21-23], our analysis takes the dynamic perspective to study how changes in the structure of a brokers' transaction network in an equity market affect the probability of qualitatively significant changes in the stock returns and in their level of activity. In other words, we present a dynamic and global analysis of the brokers' (intermediaries') transaction network, which departs from the traditional static and idiosyncratic investor or lender-agent centered approach in the literature. Specifically, we study the following hypotheses:

(1) The transaction network's structure changes with variations in the financial information set available for the market agents.

(2) Changes in the transaction network structure affect the probability of qualitatively significant variations in the returns of the traded assets.

(3) Changes in the transaction network structure affect the probability of qualitatively significant variations in the volume of the traded assets.

In order to test these hypotheses, we construct and validate a measure of how much a network structure changes over time. Such measure must consider the change in several possible dimensions to capture the complexity of a network's change. Thus, we propose a measure, summarized in an index, which synthesizes the complexity of the daily changes in the transaction network structure, using data from the Santiago Stock Exchange (SSE) ${ }^{3}$ for the period of 2006-2015. The results show that this index is sensitive to the variation of a series of local and international financial environment variables, which provides evidence to support the first hypothesis. In addition, we show that changes in the transaction network structure, captured through the index, are strongly and significantly associated with a greater probability of positive shocks on the stock return at the aggregate level. We also show that there is no evidence of a significant correlation between a change in the network structure and negative shocks on returns. These findings support the second hypothesis. Finally, we find that larger changes of the transaction network captured by the index increase the probability of a rise in traded volumes, which supports the third hypothesis.

Our results complement the financial market microstructure evidence that frictions and imperfections at the brokers' level affect asset prices and returns. This literature finds that the valuation effect of frictions at brokerage level (such as trading fees, cost of processing orders, or simply the search for counterparties in a negotiation of purchase and sale of shares) is relevant. These brokers' level frictions reduce assets' values and lead to lower securities' liquidity levels and higher short term price volatility ${ }^{4}$. However, if transaction network's changes affect returns, then the transaction network's structural change may capture sources of brokers' level frictions previously unidentified by the financial market microstructure literature ${ }^{5}$.

The rest of the paper is structured as follows: in Section 2, we describe our data ${ }^{6}$ and explain our focus on the Chilean market. Then, we explain how we characterize the network, which allows us to study how the definition of when an interaction between agents is generated also plays a role in the analysis of the network structure. Finally, we present the index that we use to summarize the structural network change. In Section 3, we present the methodology and the results of our analysis. First, we specify the econometric models used to test our hypotheses. Then, we present the main results. In Section 4, we present an analysis of robustness, and finally in the fifth section we provide our conclusions.

\section{The Data}

2.1. Main Data Sources. In order to empirically analyze the changes in the transaction network of local stockbrokers, we constructed a database with the universe of the daily stock transactions conducted by the stockbrokers at the SSE for the period of 2006-2015. This study relies on the level of detail and disaggregation of the data. The dataset includes precise information of day of transaction, instrument traded, type of operation, units exchanged, purchase price, and identification of the buying and selling brokers involved. Therefore, we are able to construct the daily transaction network for the Chilean equity market for the period of 20062015. We construct an index that synthesizes and measures the structural change of the transaction network by comparing the networks at dates $t$ and $t-1$. The details of the index are presented in Section 2.4.

Then, we use this measure of the structural change of a network (index) to econometrically study whether the changes of the network's structure are correlated with changes (evolution) of local and international financial environment variables and indicators over time ${ }^{7}$. We consider variables that are standard in the literature, and our aim is to capture all possible factors that affect stock prices. Fratzscher and others [24], Estrada and others [25], Lavigne and others [26], and Chen and others [27] describe four channels by which spillovers are transmitted from developed to emerging markets: (a) portfolio balance: portfolio rebalancing that lowers risk premiums, boosts assets prices, and lowers yields; (b) signaling or confidence: carry trade and capital flows generated by larger differentials in interests rates; (c) exchange rate: flows that generate appreciation and depreciation of exchanges rates; and (d) trade flows: changes in the demands for emerging countries' exports. According to this and the fact that Chile is an emerging country, the main local 
variables that should be affected by a shock are the IPSA blue-chip index (IPSA), which groups the 40 most liquid stocks with the greatest market capitalization on the Chilean market; the exchange rate between the Chilean peso and the dollar (CLP); the credit default swaps at 5 years of the Chilean sovereign debt (CDS5), and, as a measure of the aggregate activity of the local stockbroker network, the total traded stock volume (volume). Among the international variables, we considered the S\&P 500 Index (S\&P 500) and the Chicago Board Options Exchange Market Volatility Index (VIX) [28]. Finally, since Chile is an emerging market and is a country exposed to the evolution of commodities prices, we also include the MSCI emerging market index (MSCI) and the copper (CU) and oil (Pe) prices, as they are Chile's main export and import products, respectively [29].

2.2. Chilean Stock Market. Studying the transaction network in the SSE is interesting for several reasons. First, having exact data of the daily transactions made by brokers allows us to explore, in a dynamic setting, a part of the financial network mostly ignored by the literature ${ }^{8}$. Second, the Chilean equity market has less liquidity than the OECD average or other developing markets, but it is larger in terms of market capitalization to GDP. Third, global factors such as monetary policy in developed countries and the appetite for global risk are key cyclical factors in the liquidity of the equity market and its level of activity [30]. Fourth, the main stock market actors are pension funds managers, insurance companies, and mutual funds [31]. These entities channel their stock transactions via stockbrokers and not through the over-thecounter (OTC) market; consequently, the stock purchase and sale decisions by the main professional investors in the Chilean market are captured through the SSE broker network. Finally, Chile is a developing country with a medium level of financial development and occupies the 29th place out of a total of 62 countries $^{9}$; therefore, the lessons learned from the study of the stock market transactions and the formation of the broker network are useful for other developing countries on the road to greater financial development.

\subsection{Characterization of the Brokers' Transaction Network.} In order to construct the daily equity brokers' transaction network for the period of 2006-2015 ${ }^{10}$, we calculate the daily total amount sold from one broker to another, excluding OTC operations. The latter allows us to distinguish between the selling behavior and the buying behavior of the SSE brokers. This approach implies that, for each pair of brokers A and B, there are two possible links: A sells to B and B sells to A. Given the wide spread of amounts traded daily within a calendar year, defining when two agents are interconnected is not an easy task. We decided to consider different alternatives for this definition. First, we define a traded amount threshold above which the interconnection between the agents is granted. We construct alternative networks varying the threshold of daily traded total amounts. In particular, we report results based on thresholds defined by the second, fourth, sixth, and eighth deciles and the average of the daily transactions made within a calendar year between any

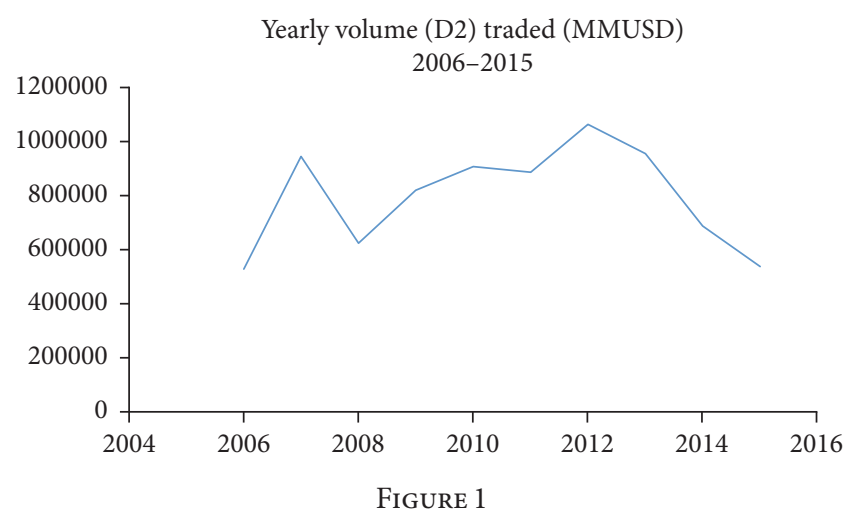

two SSE brokers. Additionally, we generated analogous results for every decile and the mode ${ }^{11}$. For each day, a link in the network indicates that the total (gross) amount of equity sold by a seller to a buyer in the day is above the threshold, as opposed to indicating that net amount sold from one broker to another exceeds the threshold. We decided to use gross sales to build a directed brokers' transaction network to minimize the information loss regarding the brokers' behavior (transaction decisions) due to two motives. First, netting transactions (within a day) generates a loss of information due to the decrease in the number of links. To illustrate the latter argument, consider the following example. Assume that the threshold considered to acknowledge a relation between two brokers is US $\$ 40$. Now, suppose that, on Monday, broker A sells US $\$ 100$ worth equity in the morning to broker B and then broker B sells US $\$ 100$ worth equity to broker A in the afternoon. If transactions were netted, the link between $\mathrm{A}$ and $\mathrm{B}$ would not be formed, and then the transaction network would not capture the actual behavior that brokers $\mathrm{A}$ and $\mathrm{B}$ exhibit by trading in the morning and in the afternoon. Second, we use a directed network to represent the transaction network to avoid information loss due to confounding the selling and buying behavior of the brokers. Considering "A selling to B" identical to "B selling to A" implicitly decreases the possible informational frictions in financial markets, which may affect returns ${ }^{12}$.

Formally, $N$ is the set of SSE brokers in the period of 2006-2015 and $G_{t}$ is the set of total transactions between brokers in $N$ in day $t$. Then, for a given $t$, the link $i j \in G_{t}$ with $i, j \in N$ indicates that the total amount sold by broker $i$ to broker $j$ in stocks, denoted by $\tau_{i j}^{t}$, is such that $\tau_{i j}^{t} \geq c$, where $c$ is the threshold for the amount traded ${ }^{13}$. Thus, $g^{t}=\left(N, G_{t}\right)$ is the directed transaction network between the brokers from $N$ in day $t^{14}$.

Figures 1, 2, and 3 show the evolution of three threshold criteria, second decile, eighth decile, and average, in current MMUSD. As can be seen, in the three figures, there is a considerable variability in the amounts traded.

Figure 4 shows how the three threshold criteria (second decile, eighth decile, and average on 3 January 2012) determine the structure of the transaction network on a given day in the sample. The structure of the transaction network defined by the "second decile traded amount" is 


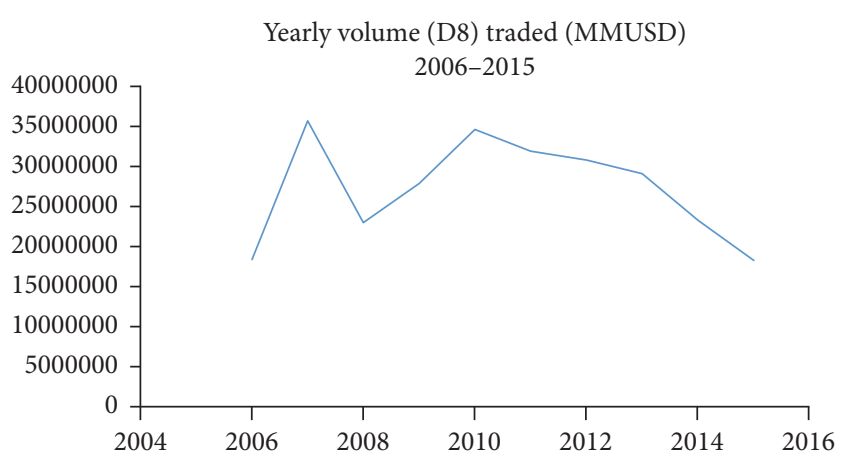

FIGURE 2

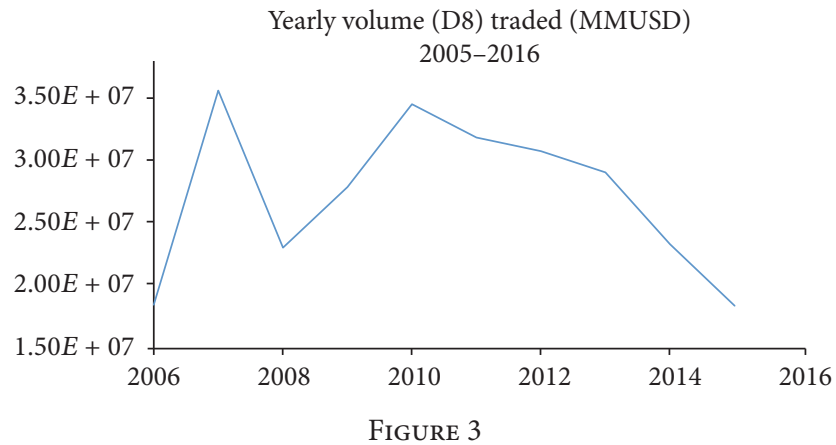

qualitatively different compared to the network defined by the "eighth decile traded amount" or "average traded amount." This qualitative difference suggests that the threshold used to define the transaction network affects the measurement of the transaction network's structural change.

In order to describe the change in $g_{t}$ over time, first we characterize the network structure using a wide set of structural characteristics. In Section 2.4, we delve deeper into why we consider several characteristics of the network structure instead of a single measure. Specifically, we calculate the ratio of brokers that trade to the total number of registered brokers in a calendar year, the ratio of sale-purchase relations to the total number of possible directed links between registered brokers, the density of $g_{t}$ (ratio of brokers to purchase-sale relations), the percentage of nodes with the same number of in-and-out degrees, the percentage of nodes with an in-degree greater than 0 (percentage of brokers that sell), the percentage of nodes with an out-degree greater than 0 (percentage of brokers that buy), the assortativity coefficient based on the number of links (indicating similarity between connected brokers based on number of links), the reciprocity coefficient, and the clustering coefficient for the network (network cohesion indicator). In addition, we determine whether the network was connected, if it had Hamiltonian cycles, if it was bipartite, if it was acyclic, if it was planar, and if it had loops. We normalized the number of nodes and directed links as explained above in order to give an equal weight to the change of any dimension used to characterize the network at $t$ and to avoid the situation where any specific characteristic of the network could skew the change in $g_{t}$ over time ${ }^{15}$. Each of these dimensions is a component of a vector of network characteristics at $t$ called $v_{t}=\left(v_{t, 1}, \ldots, v_{t, D}\right)$, where $D$ is the number of network characteristics that we include in our analysis.

2.4. Proposal of an Index of Network Change. Networks are objects that have a multiplicity of dimensions that characterize them, each one changing over time. For this reason, it is not surprising that different studies, focused on the static relation of a single characteristic of a financial network (or a part of it) with some measure of financial performance, have obtained apparently contradictory results, as previously mentioned. These apparently contradictory conclusions can be explained in at least two ways. First, there may be conditions external to the network which vary over time and explain a financial resilience that changes over time for the same network topology. This is the approach of Acemoglu and others [6] who show that the magnitude and number of negative shocks on a financial system determine if greater interconnectivity within the network increases or reduces the robustness of a banking system. Second, a network is a complex object for which each of its diverse characteristics can change over time [17]. Therefore, to assume that financial performance depends exclusively on only one specific characteristic of the network over a measurement of financial performance omits the role that other characteristics of the network, their interrelations, and the dynamics of the network structure can have on the mechanisms which determine both the functioning of the financial system and its returns and volumes traded. Then discerning between the potential causes that affect the resilience of financial systems is in essence an empirical problem. We circumvent this problem assuming that the networks are complex objects evolving over time. Moreover, the investor's broker choice and the broker's decisions on who to trade with reveal an additional aspect of the financial network, which may affect its resilience. If there are no frictions in the stock market, then the investor's broker choice should be random, and returns and volume traded should not be affected by the selection of a broker. This occurs because there is no gain from choosing one broker over another. However, if there are frictions in the stock market, then investors may decide to trade through a specific broker purposely to increase (decrease) his benefits (costs) from trade, which should affect the structure of the transaction network and its change over time. Therefore, the change of the transaction network's structure may provide information about how some financial frictions affect the stocks' returns and volumes traded. In the latter case, a structural change of the transaction network should affect the IPSA return (hypothesis 2) and volume traded (hypothesis 3 ).

Our goal is to produce a measure of the daily structural change on the transaction network. Considering the multidimensionality of the object to study, we proposed two alternative indices that capture this change:

$$
\begin{aligned}
& \kappa_{t}^{1}=\left|\left[\underset{\lambda \in \mathbb{R}}{\arg \min } \sum_{d=1}^{D}\left(\lambda \cdot v_{t, d}\left(g_{t}\right)-v_{t-1, d}\left(g_{t-1}\right)\right)^{2}\right]-1\right|, \\
& \kappa_{t}^{2}=\left[\underset{\lambda \in \mathbb{R}}{\arg \min } \sum_{d=1}^{D}\left(\lambda \cdot v_{t, d}\left(g_{t}\right)-v_{t-1, d}\left(g_{t-1}\right)\right)^{2}\right],
\end{aligned}
$$




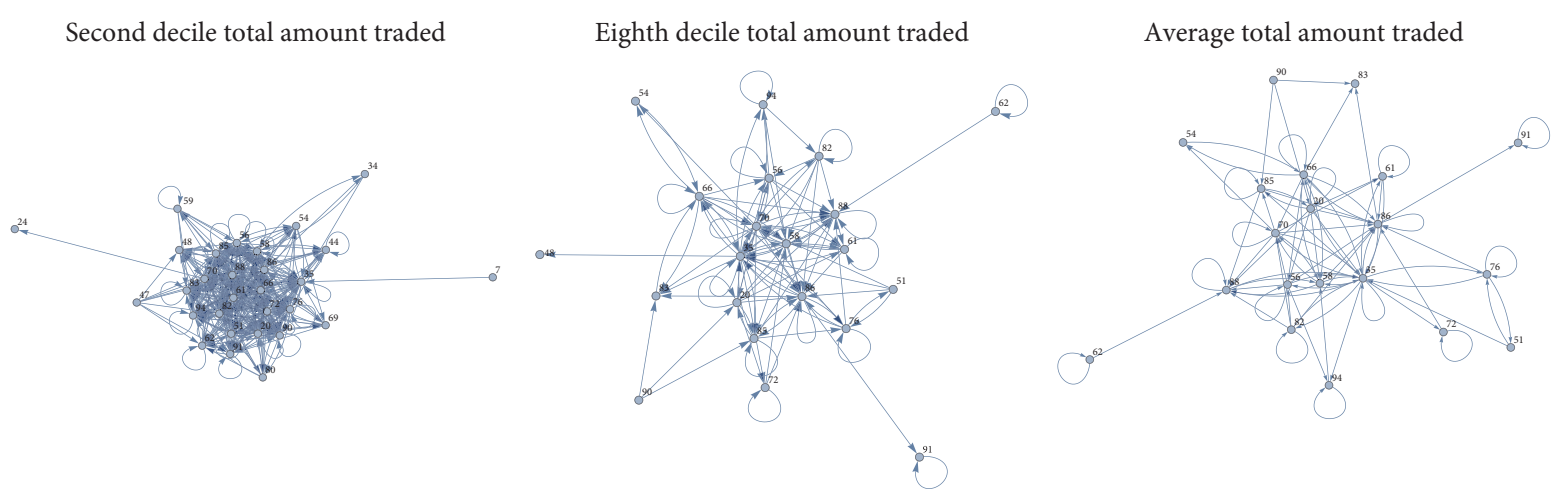

FIGURE 4

where $g_{t}$ is the transaction network at date $t$ in the SSE and $v_{t, d}$ corresponds to the $d$ th characteristic of the network $g_{t}$. That is, in both $\kappa_{t}^{1}$ and $\kappa_{t}^{2}, \lambda \in \mathbb{R}$ scales up or down the vector of network characteristics at $t$ (i.e., $v_{t}$ ) in order to make it as similar as possible to $v_{t-1}$. Thus, a smaller $\lambda$ indicates that the structural change in the transaction network in $t-1$ and $t$ is smaller. Therefore, $g^{t}$ and $g^{t-1}$ are more alike. Given these definitions, $\kappa_{t}^{1}, \kappa_{t}^{2} \in \mathbb{R}_{+}$. Both indices, $\kappa_{t}^{1}$ and $\kappa_{t}^{2}$, measure the change in the transaction network. However, $\kappa_{t}^{1}$ and $\kappa_{t}^{2}$ differ in that $\kappa_{t}^{1}$ solely indicates the magnitude of a change from $g_{t}$ to $g_{t-1}$, whereas $\kappa_{t}^{2}$ also indicates whether $g_{t}$ looks more or less alike a complete network than $g_{t-1}{ }^{16}$. That is, the difference between $\kappa_{t}^{1}$ and $\kappa_{t}^{2}$ is that $\kappa_{t}^{1}$ measures the change in the transaction network at two points in time without assigning any interpretation regarding the type of structure that the network is changing to. On one hand, $\kappa_{t}^{1}$ is best suited to study, for instance, if greater structural changes of the transaction network are positively or negatively associated with a better (or worse) performance of the financial system measured by positive (negative) jumps of the return of the market's price index ${ }^{17}$. On the other hand, $\kappa_{t}^{2}$ is best suited to study if structural changes toward a complete network have different effect than structural changes away from a complete network. The absence of change in the network at $t$ and at $t-1$ is reflected in $\kappa_{t}^{1}=0$ (and in $\kappa_{t}^{2}=1$ ). A greater daily transaction network's structural change between $t$ and $t-1$ implies a larger $\kappa_{t}^{1}$ but not necessarily a larger $\kappa_{t}^{2}$, because the latter index increases as the network changes toward the complete network. Because we are giving equal weights to every component in $v_{t}, \kappa_{t}^{1}$ can be interpreted as the magnitude (absolute value) of first difference of a summary statistic of the change between $v_{t}$ and $v_{t-1}$. Analogously, $\kappa_{t}^{2}$ can be interpreted as the first difference of a summary statistic of the change between $v_{t}$ and $v_{t-1}$.

Considering that the literature is still debating if a complete network helps or is detrimental for the financial system's resilience, we decided to focus on the role of the structural change of the network independently of the topology that the network moves to. Therefore, our preferred measure of structural change is the index $\kappa_{t}^{1}$. We present only the basic results for $\kappa_{t}^{2}$.

\section{Econometric Analysis}

3.1. Specification of the Model. As was discussed before, the first step consists in studying whether changes in the transaction network measured by the indices are correlated with the local and international financial environment variables that we described in Section 2.1. First, we empirically assess which of the two possible measures of structural change $\left(\kappa_{t}^{1}\right.$ or $\left.\kappa_{t}^{2}\right)$ better captures changes in the financial system (CLP, CDS5, VIX, MSCI, CU, and Pe). Table 1 shows the correlation between the returns or growth rate of the financial environment variables described in Section 2.1 and the two possible definitions of the index. We estimate an ordinary least squares regression where the dependent variable is the index to obtain the correlations. Adding controls for month and year allows us to isolate the correlations of seasonal variations or a specific year relationship. Table 1 shows regressions for all finance variables described above. Going forward, we focus on the relationship between the index and the financial variables that present a statistically significant correlation with the network structure.

It should be noted that, given the construction of the measures of network change $\kappa_{t}^{1}$ and $\kappa_{t}^{2}$, it is not possible to determine a priori how the financial variables will be related to the transaction network's structural change. Furthermore, the definition of when agents are linked (thresholds) and, therefore, how the transaction network is structured provides an additional degree of freedom to consider when assessing the correlation between the financial environment variables and the change in the transaction network structure.

One difference established in Table 1 between $\kappa_{t}^{1}$ and $\kappa_{t}^{2}$, which is in line with the contradictory results described in the aforementioned works, is that the measure that is neutral with respect to the interpretation of movements in the network $\left(\kappa_{t}^{1}\right)$ correlates with more financial variables than $\kappa_{t}^{2}$ and confirms our theoretical choice that $\kappa_{t}^{1}$ is the best suited index for our study. Table 1 also provides support for our first hypothesis. Specifically, the network structure moves together with the financial environment variables. Moreover, Table 1 shows that this relationship does not follow an easily discernible simple pattern. Going forward, we focus on $\kappa_{t}^{1}$, because the $\kappa_{t}^{1}$ index correlates significantly with more of the 
TABLE 1: Basic model. This table summarizes the results of the following basic model: $y_{t}=\alpha+\beta * X_{t}+m_{t}+N_{t}+\varepsilon_{t}$. The dependent variable is the proposed index of network change, calculated using the average transaction as a threshold for the existence of a link. $X_{t}$ corresponds to the returns or growth rate of variables such as IPSA, VIX, Pe, CU, CLP, S\&P 500, volume, CDS5, and MSCI. $m_{t}$ and $N_{t}$ are month and year fixed effects to control for seasonality and variation associated with any specific year. Columns (1) and (2) show the results for the indexes $\kappa_{t}^{1}$ and $\kappa_{t}^{2}$, and column (3) displays our preferred specification.

\begin{tabular}{|c|c|c|c|}
\hline \multirow{2}{*}{ Variables } & $(1)$ & $(2)$ & (3) \\
\hline & Average $\left(\kappa^{1}\right)$ & Average $\left(\kappa^{2}\right)$ & Average $\left(\kappa^{1}\right)$ \\
\hline \multirow{2}{*}{ VIX } & $0.112^{* * *}$ & $-0.187^{* * *}$ & $0.109^{* * *}$ \\
\hline & [0.0412] & {$[0.0629]$} & {$[0.0410]$} \\
\hline \multirow{2}{*}{ IPSA } & $-0.605^{* *}$ & 0.327 & $-0.554^{* *}$ \\
\hline & [0.280] & {$[0.377]$} & [0.277] \\
\hline \multirow{2}{*}{ MSCI } & $0.481^{* *}$ & -0.487 & $0.556^{* *}$ \\
\hline & [0.243] & {$[0.305]$} & [0.242] \\
\hline \multirow{2}{*}{$\mathrm{Pe}$} & $-0.372^{* * *}$ & 0.193 & $-0.316^{* * *}$ \\
\hline & [0.126] & {$[0.145]$} & [0.115] \\
\hline \multirow{2}{*}{$\mathrm{CU}$} & 0.218 & -0.235 & \\
\hline & [0.153] & [0.187] & \\
\hline \multirow{2}{*}{ S\&P 500} & $0.698^{* * *}$ & $-0.948^{* *}$ & $0.679^{* *}$ \\
\hline & {$[0.270]$} & [0.386] & {$[0.269]$} \\
\hline \multirow{2}{*}{ CLP } & $0.876^{* *}$ & -0.451 & $0.719^{*}$ \\
\hline & [0.394] & {$[0.541]$} & {$[0.376]$} \\
\hline \multirow{2}{*}{ CDS5 } & -0.0230 & 0.0690 & \\
\hline & {$[0.0651]$} & {$[0.0832]$} & \\
\hline \multirow{2}{*}{ Volume } & -0.00145 & $-0.0158^{* * *}$ & \\
\hline & {$[0.00375]$} & {$[0.00448]$} & \\
\hline \multirow{2}{*}{ Constant } & $0.133^{* * *}$ & $0.930^{* * *}$ & $0.135^{* * *}$ \\
\hline & {$[0.0122]$} & {$[0.0143]$} & {$[0.0118]$} \\
\hline Observations & 2,340 & 2,340 & 2,352 \\
\hline$R$-squared & 0.036 & 0.028 & 0.035 \\
\hline
\end{tabular}

Robust standard errors are given in brackets. ${ }^{* * *} p<0.01,{ }^{* *} p<0.05$, and ${ }^{*} p<0.1$.

financial system variables, and it is our theoretical index of choice $^{18}$.

To deepen our understanding of how the financial system is related to the transaction network's structure, we analyze the correlations presented in Table 1 for different thresholds that define the links that form the network. For instance, using the second decile as a threshold implies that most of the transactions are able to establish links among the agents, and therefore the transaction network's structure changes "little" and constantly due to the daily financial fluctuations. On the other hand, if we use the eighth decile, the only links generated are associated with transactions that are relatively extraordinary. Therefore, the transaction network that is formed in this case is associated with high volume transactions that occur only seldom within a year. Thus, any such network can be expected to change "more dramatically" than networks defined by smaller thresholds.

Another interesting result stemming from Table 1 is the lack of correlation between traded volume and the index. One possible concern regarding the informational content of the index is that changes in financial activity may endogenously affect the transaction network's structure through the creation and destruction of links and nodes.
However, by construction, $\kappa_{t}^{1}$ and $\kappa_{t}^{2}$ capture many topological characteristics of $g_{t}$ such as cyclicality and planarity and thus not only reflect changes in the number of links and nodes. This defining characteristic of the indices alleviates the endogeneity concerns. Moreover, the results in Table 1 indicate that these latter network topological characteristics are playing an important role in the index, and consequently traded volume is, indeed, not correlated with the index.

In Table 2, the results of the estimation presented in Table 1 are compared, but using deciles 2, 4, 6, and 8 as well as the average as the threshold definition, we can see that, for the transaction network defined with the average, changes in the VIX, IPSA, MSCI, Pe, S\&P 500, and CLP correlate with the network showing more structural changes ${ }^{19}$. It is worth noting that as we move up on the deciles, only the VIX and the S\&P 500 show correlation with the index when the threshold is set to the eighth decile. This result suggests that changes of external factors correlate with changes of the transaction network defined by low volume transactions threshold (lower deciles) or by less common high volume transactions threshold (higher deciles).

Now, to better understand how changes in the transaction threshold define how the network is constructed, 
TABLE 2: Basic model using different thresholds. This table summarizes the results of the following basic model: $y_{t}=\alpha+\beta * X_{t}+m_{t}+N_{t}+\varepsilon_{t}$. The dependent variable is the proposed index of network change for different thresholds that define a link. $X_{t}$ corresponds to the returns or growth rate of variables such as IPSA, VIX, Pe, S\&P 500, CLP, and MSCI. $m_{t}$ and $N_{t}$ are month and year fixed effects to control for seasonality and variation associated with any specific year. Column (1) uses the average transaction as a threshold. Columns (2) to (5) use the second, fourth, sixth, and eighth deciles as thresholds.

\begin{tabular}{|c|c|c|c|c|c|}
\hline \multirow{2}{*}{ Variables } & (1) & (2) & (3) & (4) & $(5)$ \\
\hline & Average & Second decile & Fourth decile & Sixth decile & Eighth decile \\
\hline \multirow{2}{*}{ VIX } & $0.109^{* * *}$ & $0.0735^{* *}$ & -0.00858 & 0.0443 & $0.119^{* * *}$ \\
\hline & {$[0.0410]$} & {$[0.0372]$} & {$[0.0381]$} & {$[0.0334]$} & {$[0.0372]$} \\
\hline \multirow{2}{*}{ IPSA } & $-0.554^{* *}$ & 0.0845 & -0.248 & -0.237 & -0.0450 \\
\hline & [0.277] & {$[0.183]$} & {$[0.248]$} & {$[0.194]$} & {$[0.233]$} \\
\hline \multirow{2}{*}{ MSCI } & $0.556^{* *}$ & 0.202 & 0.129 & 0.122 & 0.113 \\
\hline & [0.242] & {$[0.135]$} & {$[0.161]$} & {$[0.171]$} & {$[0.165]$} \\
\hline \multirow{2}{*}{$\mathrm{Pe}$} & $-0.316^{* * *}$ & -0.0818 & -0.0138 & -0.0175 & -0.0519 \\
\hline & [0.115] & {$[0.0795]$} & {$[0.0711]$} & {$[0.0712]$} & {$[0.0796]$} \\
\hline \multirow{2}{*}{ S\&P 500} & $0.679^{* *}$ & $0.381^{*}$ & 0.0800 & $0.374^{* *}$ & $0.821^{* * *}$ \\
\hline & [0.269] & {$[0.218]$} & [0.195] & {$[0.173]$} & {$[0.220]$} \\
\hline \multirow{2}{*}{ CLP } & $0.719^{*}$ & $0.606^{* *}$ & 0.184 & 0.478 & 0.219 \\
\hline & {$[0.376]$} & [0.276] & [0.331] & [0.323] & [0.269] \\
\hline \multirow{2}{*}{ Constant } & $0.135^{* * *}$ & $0.0699^{* * *}$ & $0.0636^{* * *}$ & $0.0623^{* * *}$ & $0.102^{* * *}$ \\
\hline & [0.0118] & {$[0.0104]$} & {$[0.00879]$} & {$[0.00638]$} & [0.00933] \\
\hline Observations & 2,352 & 2,352 & 2,352 & 2,352 & 2,352 \\
\hline$R$-squared & 0.035 & 0.032 & 0.028 & 0.016 & 0.025 \\
\hline
\end{tabular}

Robust standard errors are given in brackets. ${ }^{* * *} p<0.01,{ }^{* *} p<0.05$, and ${ }^{*} p<0.1$.

TABle 3: Descriptive statistics of the network structure. This table summarizes the descriptive statistics of the network structure in terms of the number of links and nodes for the second, fourth, sixth, and eighth deciles.

\begin{tabular}{lcccccccc}
\hline & \multicolumn{4}{c}{ Number of links } & \multicolumn{3}{c}{ Number of nodes } \\
& Second decile & Fourth decile & Sixth decile & Eighth decile & Second decile & Fourth decile & Sixth decile & Eighth decile \\
\hline Average & 412.66 & 309.79 & 206.72 & 103.46 & 30.93 & 28.49 & 25.48 & 20.85 \\
Median & 413.00 & 310.00 & 204.00 & 101.00 & 31.00 & 28.00 & 26.00 & 21.00 \\
Mode & 430.00 & 275.00 & 206.00 & 101.00 & 31.00 & 28.00 & 26.00 & 20.00 \\
Std. dev. & 56.15 & 49.99 & 42.00 & 29.31 & 2.29 & 2.11 & 1.98 & 2.24 \\
\hline
\end{tabular}

Table 3 shows descriptive statistics about the structure of the networks formed with different thresholds (second, fourth, sixth, and eighth decile and the average for the daily amount traded). The table shows that when we increase the decile that defines the threshold, the average number of links in the network is reduced substantially. In particular, it drops from 412 links on average when using the second decile to only 103 links on average for the eighth decile. This decrease is also noted in the number of brokers involved, which lowers from 30 to 20 . Nevertheless, the fall in the number of links is more dramatic, since it is a drop close to $75 \%$ versus a decrease of $33 \%$ in the number of active brokers when rising from the second to the eighth decile.

Another interesting aspect is that in relative terms the network formed with thresholds associated with higher deciles is more volatile in the number of links than the networks made up of less restrictive thresholds.

One important concern when studying the correlation between the index and the returns of the financial variables is the possibility of autocorrelation in the index. That is, we want to determine if the index is correlated with contemporaneous returns of financial variables or if it is the lagged index that is correlated with contemporaneous returns of financial variables. Table 4 shows estimations of the model presented in Table 1 , adding lags of 1 and 2 days of the index. Other autocorrelation structures were estimated ${ }^{20}$, but the time lags beyond two days are not statistically significant. Table 4 shows that the index constructed using the average amount daily traded shows no autocorrelation. For the second and fourth deciles, the index tends to reduce its change after one day $^{21}$. For the eighth decile, if there were structural changes in the network yesterday, it is very possible that changes are occurring today. These autocorrelations show that the changes in the network structure are relatively localized over time and are not long-term trends.

In order to analyze econometrically if the index $\kappa_{t}^{1}$ is able to capture a relationship between changes of the transaction network and changes in the local and international financial environment variables, we define a shock to variable $x$ as the change of two standard deviations on the value of $x$. We 
TABLE 4: Basic model controlling for autocorrelation. This table summarizes the results of the following model: $y_{t}=\alpha+\beta * X_{t}+\gamma_{1} * y_{t-1}+$ $\gamma_{2} * y_{t-2}+m_{t}+N_{t}+\varepsilon_{t}$. The dependent variable is the proposed index of network change for different thresholds that define a link. We add to the basic model the index lagged in one and two days to study possible autocorrelation. $X_{t}$ corresponds to the returns or growth rate of variables such as IPSA, VIX, Pe, CLP, S\&P 500, and MSCI. $m_{t}$ and $N_{t}$ are month and year fixed effects to control for seasonality and variation associated with any specific year. Column (1) uses the average transaction as a threshold. Columns (2) to (5) use the second, fourth, sixth, and eighth deciles as thresholds.

\begin{tabular}{|c|c|c|c|c|c|}
\hline \multirow{2}{*}{ Variables } & (1) & (2) & $(3)$ & $(4)$ & (5) \\
\hline & Average & Second decile & Fourth decile & Sixth decile & Eighth decile \\
\hline \multirow{2}{*}{ VIX } & $0.107^{* * *}$ & $0.0758^{* *}$ & -0.00762 & 0.0424 & $0.110^{* * *}$ \\
\hline & {$[0.0410]$} & {$[0.0373]$} & {$[0.0380]$} & {$[0.0334]$} & {$[0.0374]$} \\
\hline \multirow{2}{*}{ IPSA } & $-0.562^{* *}$ & 0.0818 & -0.241 & -0.238 & -0.0739 \\
\hline & [0.277] & {$[0.184]$} & {$[0.248]$} & {$[0.195]$} & {$[0.230]$} \\
\hline \multirow{2}{*}{ MSCI } & $0.550^{* *}$ & 0.221 & 0.124 & 0.120 & 0.0482 \\
\hline & {$[0.242]$} & {$[0.135]$} & {$[0.162]$} & {$[0.171]$} & {$[0.163]$} \\
\hline \multirow{2}{*}{$\mathrm{Pe}$} & $-0.319^{* * *}$ & -0.0814 & -0.0104 & -0.0198 & -0.0352 \\
\hline & [0.115] & {$[0.0795]$} & {$[0.0715]$} & {$[0.0714]$} & {$[0.0794]$} \\
\hline \multirow{2}{*}{ S\&P 500} & $0.679^{* *}$ & $0.387^{*}$ & 0.0829 & $0.369^{* *}$ & $0.827^{* * *}$ \\
\hline & {$[0.268]$} & {$[0.218]$} & {$[0.195]$} & {$[0.173]$} & {$[0.223]$} \\
\hline \multirow{2}{*}{ CLP } & $0.716^{*}$ & $0.633^{* *}$ & 0.182 & 0.477 & 0.225 \\
\hline & {$[0.377]$} & {$[0.276]$} & [0.332] & {$[0.323]$} & [0.267] \\
\hline \multirow{2}{*}{ Index lagged 1 day } & 0.0182 & $-0.0553^{* * *}$ & $-0.0314^{* *}$ & 0.00869 & $0.0921^{* * *}$ \\
\hline & {$[0.0193]$} & {$[0.0126]$} & {$[0.0150]$} & {$[0.0172]$} & {$[0.0236]$} \\
\hline \multirow{2}{*}{ Index lagged 2 days } & -0.00677 & -0.00574 & 0.0149 & -0.0189 & $-0.0286^{*}$ \\
\hline & [0.0199] & {$[0.0225]$} & {$[0.0244]$} & [0.0192] & {$[0.0173]$} \\
\hline \multirow{2}{*}{ Constant } & $0.132^{* * *}$ & $0.0744^{* * *}$ & $0.0647^{* * *}$ & $0.0628^{* * *}$ & $0.0914^{* * *}$ \\
\hline & {$[0.0128]$} & {$[0.0108]$} & [0.00889] & {$[0.00654]$} & {$[0.00860]$} \\
\hline Observations & 2,351 & 2,351 & 2,351 & 2,351 & 2,351 \\
\hline$R$-squared & 0.036 & 0.035 & 0.029 & 0.016 & 0.034 \\
\hline
\end{tabular}

Robust standard errors are given in brackets. ${ }^{* * *} p<0.01,{ }^{* *} p<0.05$, and ${ }^{*} p<0.1$.

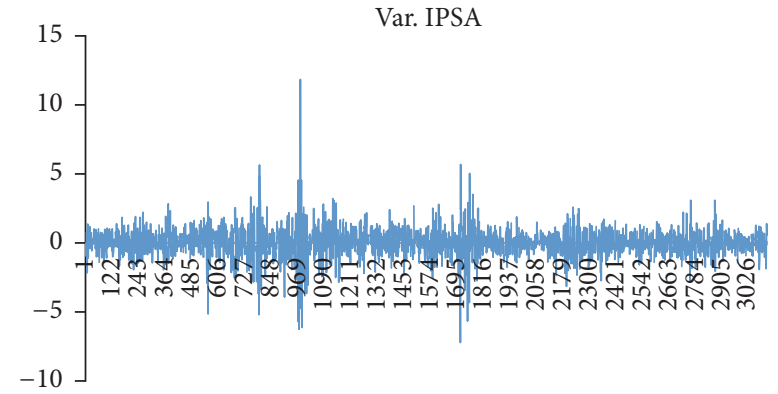

FIGURE 5

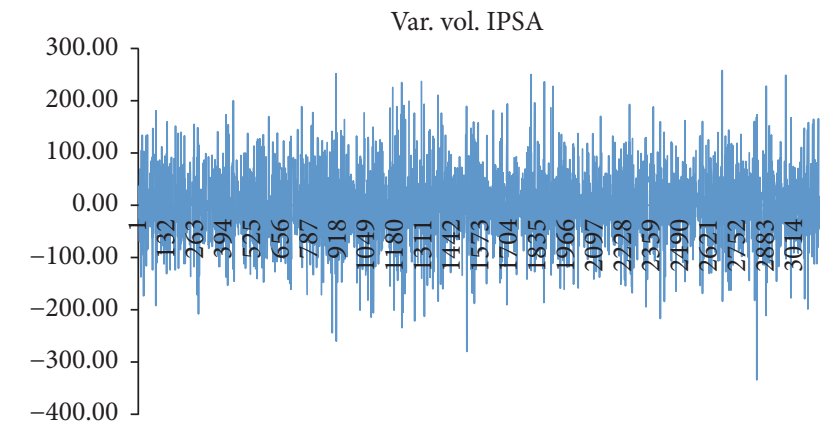

Figure 6 differentiate positive and negative changes, and we focus on shocks to stock returns (IPSA returns) and volume traded. We construct a daily dummy variable upward (downward) shock $_{i t y}$ that takes the value of 1 if the daily variation of variable $i$ on day $t$ of year $y$ is greater than two standard deviations above the average daily variation of $i$ in year $y$ (upward). Thus, taking the IPSA equity market return as an example, out of a total of 3,130 daily observations (see Figure 5), we obtained 311 upward and 85 downward 2-sigma shocks. In the case of the volume traded on the market (see Figure 6), we obtained 347 upward and 80 downward 2-sigma shocks.
Figure 7 illustrates all the 2-sigma shocks generated in the period of 2006-2015 for all the variables described in Section 2.1.

As Figure 7 shows, there are a significant number of financial shocks in the market. In terms of the variability of these events, it is observed that over time there is no uniformity in these shocks. This could suggest that if these shocks are related to changes in the financial network, the network possibly could affect the behavior of the market as a whole. In the next section, we study if changes in the 


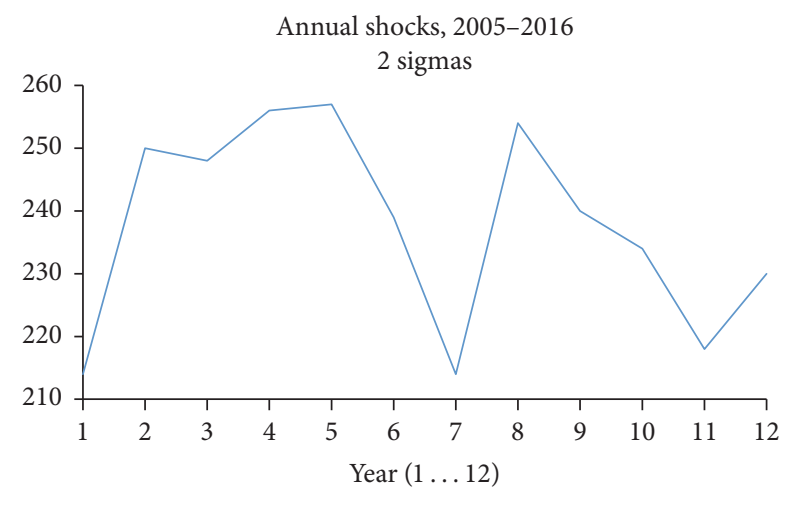

Figure 7

transaction network are correlated with these episodes of positive and negative shocks to returns and volume.

\subsection{Main Results}

3.2.1. Types of Transaction and Movements in the Equity Market. The previous results indicate a correlation between changes in the transaction network and movements in the financial variables. However, we are interested in learning if the change in the transaction network may have significant effects on both returns and volume.

In order to avoid the situation in which the threshold defining the network is relevant for our main results, the estimations are shown for different thresholds. These different networks allow us to observe econometrically both the performance of the index and what type of transaction network performs statistically better.

First, we estimate a probit model, where the dependent variable $I_{t}$ is 0 when there is no shock and takes the value of 1 when a positive shock of two standard deviations affects the IPSA. In other words, we estimate the following equation:

$$
\operatorname{Pr}\left(I_{t}=1\right)=\Phi\left(\alpha+\lambda * y_{t}+\beta * X_{t}+m_{t}+N_{t}\right),
$$

where $y_{t}$ is the index at time $t$ to measure how much the transaction network structure has changed from $t-1$ to $t$. $X_{t}$ is a set of finance variables, expressed in returns or growth rates, such as IPSA, VIX, Pe, CLP, S\&P 500, and MSCI. $m_{t}$ and $N_{t}$ are month and year fixed effects to control for seasonality and variation associated with any specific year.

Panel A in Table 5 shows the results of this model for networks constructed with the aforementioned thresholds. Surprisingly, mainly no contemporaneous change in financial variables statistically increases or decreases the probability of a positive shock. Note, however, that a contemporaneous change in the network structure, captured through variations of the index, increases the probability that there will be a positive shock. This implication holds true for all possible thresholds. In other words, structural changes in the transaction network defined by low volume transaction threshold or high volume transaction threshold increase the probability of a substantial positive shock on stock returns.

Yet, it is possible that the index is related to the probability of a positive shock with a certain time lag. Panel B in Table 5 shows estimations for the probit, when a time lag is included for the index $\left(\kappa_{t}^{1}\right)$, for the same networks constructed with different thresholds. In light of the results presented in Table 4, we only use one lag for the autocorrelation structure. It is clear from panel B that only the contemporaneous structural change of the network is correlated with the probability of a positive shock.

Table 5 shows that changes in the network structure, captured through the index, are not only correlated with the financial variables but are also capturing relevant information at brokers level or at market level, which are not seized by other aggregate financial variables about positive shocks in the financial system, such as good corporate results, better growth prospects, and political changes. Additionally, this result is robust even when we change the threshold that defines the network. Then, the index makes it possible to systematically analyze how the structural changes in the highly complex and volatile networks associated with transactions in the financial market are related to the performance of the financial returns. These results indicate that the brokers' network matters for the market behavior and performance, in line with Easley and O'Hara [2] and Vayanos and Wang [3].

However, it is possible that positive shocks and negative shocks are different in nature. One possible difference may be related to how information is transmitted through the transaction network. It is plausible that negative shocks are mostly unexpected, but positive shocks go through an information-diffusion process. In the latter process, more informed agents or brokers could act first, thereby transmitting private information to other less informed agents. One possible interpretation of Table 5 is that the change in the network structure is correlated to positive shocks on returns due to the information-diffusion process through transaction among informed brokers. Therefore, one interesting test is to study how the changes in the network correlate with unexpected shocks.

Table 6 shows the estimation of a probit model to study the correlation between the structural change of the network and large negative shocks to the IPSA return (greater than two standard deviations). We present the results controlling for possible autocorrelation, but they are similar for the specification without including the lagged index. Table 6 shows that the contemporaneous change of the transaction network is not correlated with the probability of a negative shock. This result is consistent with the notion of an unexpected shock that does not affect the network structure. Moreover, other contemporaneous financial variables display correlation with the negative shock. For instance, an increase in the percentage change of oil price $(\mathrm{Pe})$ augments the probability of a negative shock in the stocks return. Similarly, a drop in the S\&P 500 (return) leads to an increase in the probability of a negative shock in the stocks return. These results indicate that our estimations are able to capture contemporaneous changes that affect the probability of substantial changes in the IPSA returns.

\section{Additional Analysis}

We present additional econometric analyses to provide further insights and to test the robustness of the main result. 


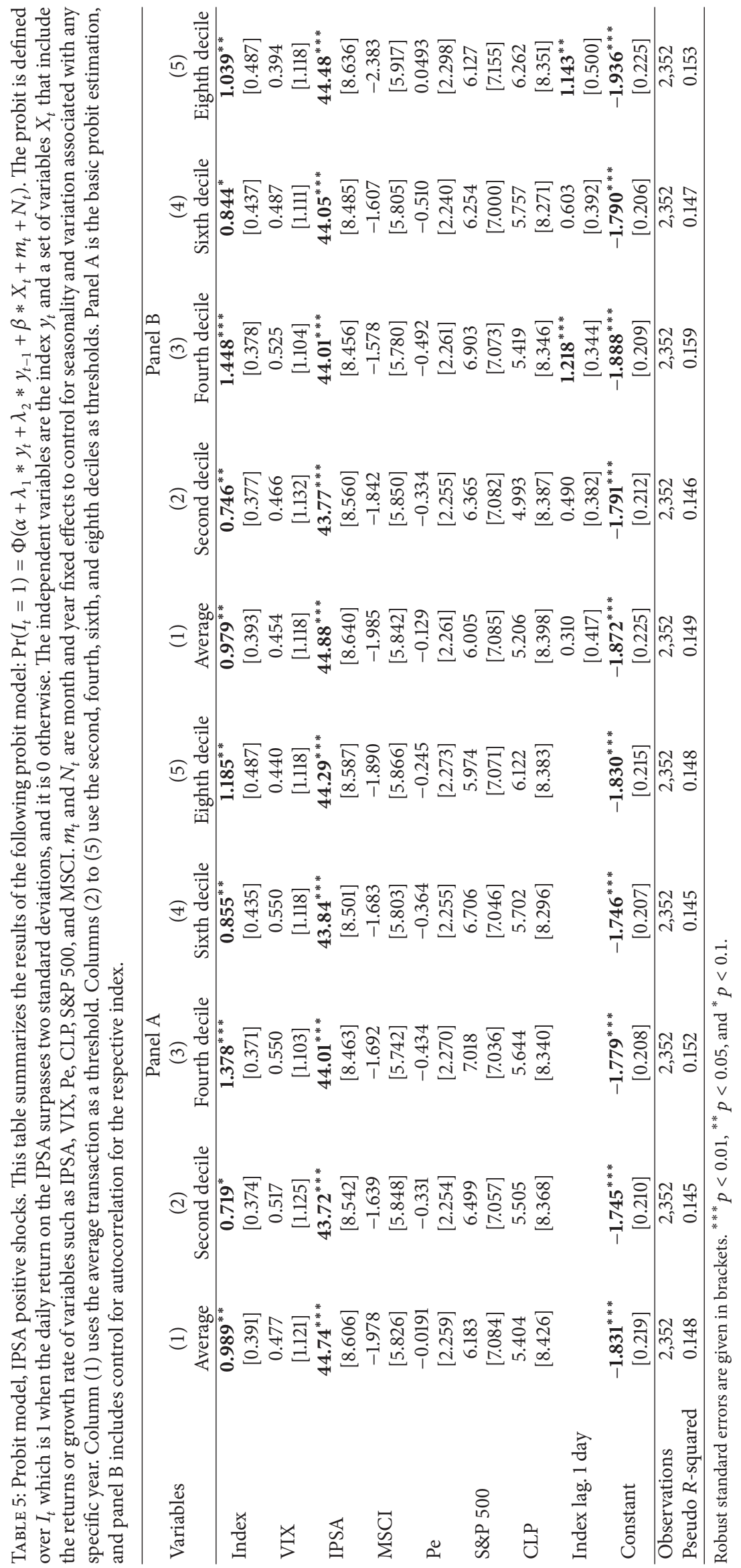


TABLE 6: Probit model, IPSA negative shocks. This table summarizes the results of the following probit $\operatorname{model}: \operatorname{Pr}\left(I_{t}=1\right)=\Phi\left(\alpha+\lambda_{1} * y_{t}+\right.$ $\left.\lambda_{2} * y_{t-1}+\beta * X_{t}+m_{t}+N_{t}\right)$. The probit is defined over $I_{t}$ which is 1 when the daily losses on the IPSA surpass two standard deviations, and it is 0 otherwise. The independent variables are the index $y_{t}$ and a set of variables $X_{t}$ that include the returns or growth rate of variables such as IPSA, VIX, Pe, CLP, S\&P 500, and MSCI. $m_{t}$ and $N_{t}$ are month and year fixed effects to control for seasonality and variation associated with any specific year. Column (1) uses the average transaction as a threshold. Columns (2) to (5) use the second, fourth, sixth, and eighth deciles as thresholds.

\begin{tabular}{|c|c|c|c|c|c|}
\hline \multirow{2}{*}{ Variables } & $(1)$ & $(2)$ & $(3)$ & $(4)$ & $(5)$ \\
\hline & Average & Second decile & Fourth decile & Sixth decile & Eighth decile \\
\hline \multirow{2}{*}{ Index } & -0.0989 & -0.319 & -0.448 & 0.956 & -1.210 \\
\hline & {$[0.736]$} & {$[0.674]$} & {$[0.708]$} & {$[0.670]$} & {$[1.056]$} \\
\hline \multirow{2}{*}{ VIX } & -2.001 & -1.799 & -1.972 & -2.130 & -2.099 \\
\hline & [1.555] & [1.547] & [1.560] & [1.537] & [1.541] \\
\hline \multirow{2}{*}{ IPSA } & $-144.2^{* * *}$ & $-146.1^{* * *}$ & $-144.9^{* * *}$ & $-145.8^{* * *}$ & $-148.1^{* * *}$ \\
\hline & [23.26] & [23.13] & [23.05] & [23.09] & [23.39] \\
\hline \multirow{2}{*}{ MSCI } & 2.009 & 3.782 & 2.454 & 2.940 & 2.748 \\
\hline & {$[10.25]$} & [10.49] & {$[10.50]$} & {$[10.60]$} & [10.81] \\
\hline \multirow{2}{*}{$\mathrm{Pe}$} & $11.33^{* * *}$ & $11.13^{* * *}$ & $11.02^{* * *}$ & $11.01^{* * *}$ & $11.43^{* * *}$ \\
\hline & [3.384] & [3.327] & [3.345] & [3.297] & {$[3.410]$} \\
\hline \multirow{2}{*}{ S\&P 500} & $-25.06^{* *}$ & $-24.41^{* *}$ & $-24.60^{* *}$ & $-26.45^{* *}$ & $-26.58^{* *}$ \\
\hline & [10.32] & [10.13] & [10.23] & [10.53] & [10.53] \\
\hline \multirow{2}{*}{ CLP } & -7.024 & -7.076 & -6.786 & -8.895 & -7.219 \\
\hline & {$[13.54]$} & [13.47] & {$[13.43]$} & {$[13.45]$} & [13.19] \\
\hline \multirow{2}{*}{ Index lag. 1 day } & -0.259 & $-1.962^{* *}$ & -0.506 & -0.652 & $-2.891^{* *}$ \\
\hline & [0.828] & [0.992] & [0.748] & [0.978] & [1.451] \\
\hline \multirow{2}{*}{ Constant } & $-3.104^{* * *}$ & $-3.064^{* * *}$ & $-3.100^{* * *}$ & $-3.168^{* * *}$ & $-2.804^{* * *}$ \\
\hline & [0.395] & [0.415] & [0.412] & [0.412] & [0.422] \\
\hline Observations & 2,352 & 2,352 & 2,352 & 2,352 & 2,352 \\
\hline Pseudo $R$-squared & 0.593 & 0.597 & 0.594 & 0.595 & 0.603 \\
\hline
\end{tabular}

Robust standard errors are given in brackets. ${ }^{* * *} p<0.01$ and ${ }^{* *} p<0.05$.

The financial literature indicates that price changes tend to be accompanied by changes in the transaction volume. For example, Huddart and others [32] show that the transaction volume significantly increases in the case of stock price changes higher or lower than their past trading range. For this reason, we study whether structural changes of the transaction network are also correlated with an increase in the probability that substantial changes in the traded volumes are observed. Table 7 shows estimations for positive and negative shocks to the traded volume ${ }^{22}$. Not surprisingly, our results suggest that the structural change of the network has a positive and significant effect on the probability of a positive shock on the traded volume. However, when studying the probability of a negative shock, the index (constructed with networks defined by different daily amount traded thresholds) shows no correlation with the negative shock. However, both the index and the lagged index show a negative correlation with a negative shock in the volume.

This result reinforces the idea that contemporaneous structural changes of the transaction network have an effect on the financial market behavior. As with the case of returns, this result is consistent across thresholds, and, therefore, we conclude that structural change of a transaction network is pertinent (significantly correlated) for the positive shocks on returns and traded volume regardless of the threshold considered to construct the network.
Finally, we calculate all the marginal effects for the average amount daily traded for each variable for the probit regressions displayed above $e^{23}$. The latter calculations show, consistently, that a change of the transaction network's structure has a positive and statistically significant effect on the probability of a positive shock in returns or volume.

\section{Conclusions}

The financial transactions may depend on the information withheld by the investors. However, the brokers' transaction network reflects the decisions that brokers make based on their own available information (public or private). We show that these latter decisions affect the returns and volume of the assets traded in the Santiago Stock Exchange (SSE) equity market. In this study, we generate a measure of the change of the brokers' transaction network based on several characteristics of the transaction network's structure in the SSE. This measure, which we call the $\kappa_{t}^{1}$ index, is able to capture the complexity of the dynamic evolution of this structure over time. Using an econometric analysis, we show that this index is sensitive to the variation of a series of local and international financial variables, which suggests that the transaction network structure is sensitive to the change in the economic/financial information available to the 


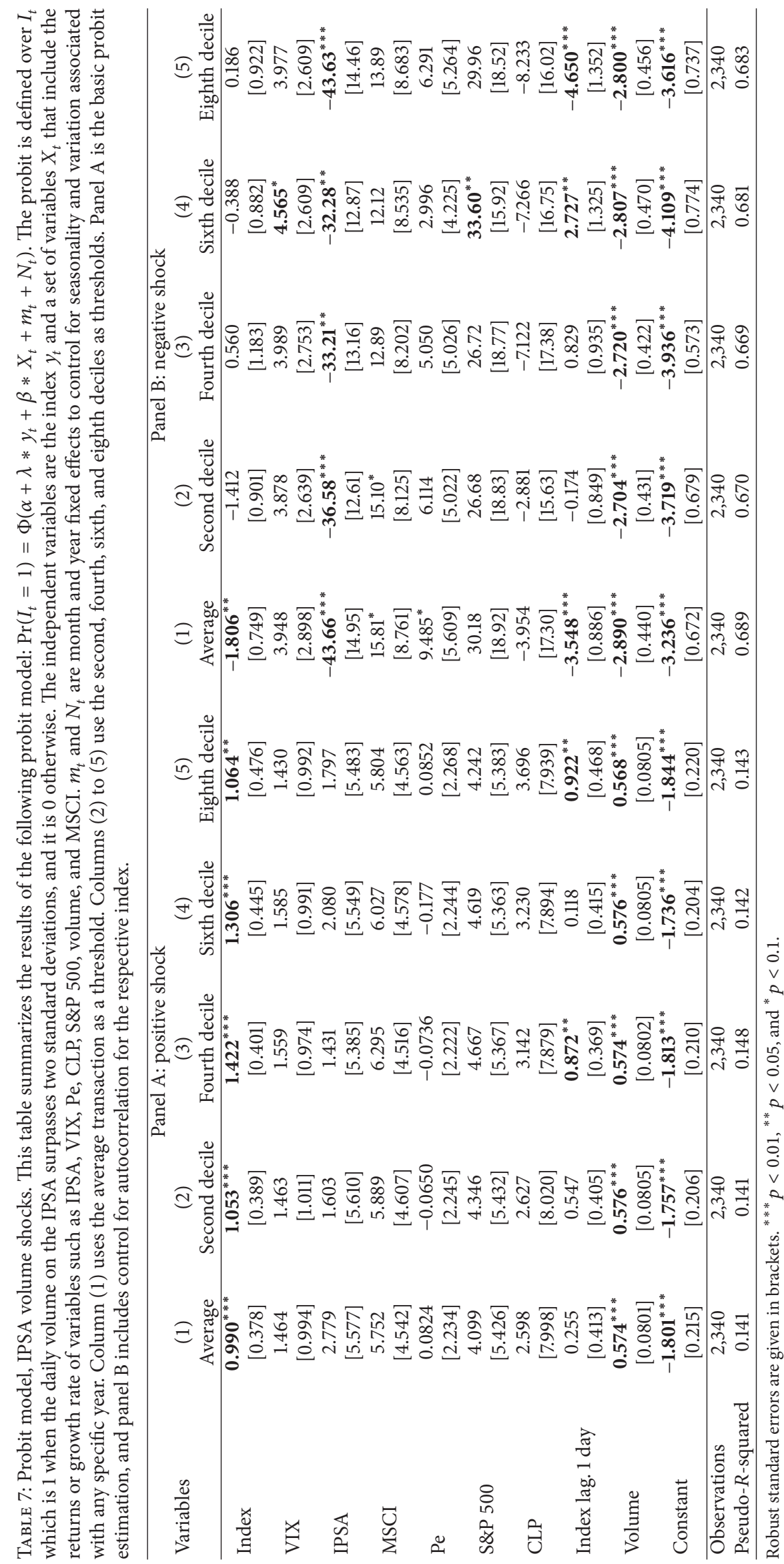


participants of that market. Using a study of cases with significant price movements, we show that changes in the index and thus in the network structure are significantly associated with a greater probability of positive shocks on the stocks' returns and traded volume. Nevertheless, there is no consistent significant correlation between the change in the network and negative shocks. This asymmetry in the relation of the transaction network's structure and shocks on the stocks' returns and volume suggests that contemporaneous changes of the transaction network to positive shocks on the IPSA returns respond to information or signals spread from brokers who trade large volumes to brokers who trade smaller volumes. On the other hand, the absence of a robust and significant relation between changes of the transaction network and negative shocks to the IPSA returns suggests that negative shocks are not accompanied by a flow of information in the transaction network. Therefore, the agents in the market cannot rationally internalize their consequences or anticipate them either. Furthermore, we show that our index is correlated positively and significantly with important changes in the transaction volume observed. In terms of possible mechanisms that can explain our results, the literature in market microstructure provides a natural relationship between volume traded and returns of an asset. Our more aggregate study of the relationship between the transaction network and the probability of positive changes on volume and returns may be capturing this natural relationship between volume and returns. We conjecture that further research in how changes in the structure of the network affect returns and volume would complement the microstructure literature in terms of both new frictions at the brokers' level and how volume can affect returns.

Therefore, our study provides evidence that suggests that the structural changes of the transaction network correlate with variations in the set of financial information available for the agents in the market (hypothesis 1), that structural changes of the transaction network affect the occurrence probability of qualitatively significant returns variations of the traded assets (hypothesis 2), and that structural changes of the transaction network affect the occurrence probability of qualitatively significant variations in the volume of traded assets (hypothesis 3). Finally, our results propose an alternative to study dynamically several characteristics of a transaction network simultaneously. This approach serves as a basis for future studies about how the structural changes of the transaction network of the equity market affect systemic risk. We believe that a promising avenue would be to establish the link between the change in the probability of a positive shock on the stock returns and the change in the financial position of the brokers.

\section{Conflicts of Interest}

The authors declare that they have no conflicts of interest regarding the publication of this paper.

\section{Acknowledgments}

The authors acknowledge the comments and observations of the participants in the Economics and Finance Seminar at the
Universidad Adolfo Ibáñez. They also acknowledge the Bolsa de Comercio de Santiago de Chile for giving them access to the data they used in this paper.

\section{Endnotes}

1. This property, known as "robust-yet-fragile" in financial networks, exhibits nonlinear dynamics. In other words, small shocks can cause large chain reactions.

2. In order to measure the relative importance of a node within a network, numerous measures such as volume of transactions, links, connectivity, and reciprocity have been used to identify the nodes of systematically important financial institutions (SIFIs). Kuzubaş and others [33] and Martínez-Jaramillo and others [34] show that centrality measures applied to risk analysis are a useful tool in the ex post analysis of a crisis, because they provide a good understanding for a subsequent financial regulation as they identify those institutions that are "too interconnected too fail". However, the existence of nonlinearities in the network interactions means that the centrality measures are not always the best tool to estimate the systemic importance and contribution to the systemic risk of a financial institution. Acemoglu and others [6] show that, in the presence of large shocks, the commonly applied centrality measures in empirical works fail to identify the SIFIs.

3. Bolsa de Comercio de Santiago de Chile (BCS) in Spanish.

4. See Stoll [1] for a survey.

5. The financial market microstructure literature identifies two sources of frictions. Some frictions are the result of the asset-associated characteristics (opacity, corporate governance, etc.). The second source of frictions is associated with the brokers, such as size or financial position.

6. The key relational data in this study were provided by the SSE in anonymized form, with no association between the brokers' names and their transactions.

7. All the data used to construct the change of the local and international financial variables were obtained from the BLOOMBERG and SEBRA terminals at the SSE (http://www.sebra.cl).

8. Namely, the intermediaries'/brokers' transaction network.

9. World Economic Forum. The Financial Development Report 2012. (https://www.weforum.org).

10. It should be noted that SSE assigns a code to each stockbroker; therefore, we did not identify them by name.

11. The interested reader can require the results for the transaction networks based on nonreported deciles and the mode from the authors.

12. In addition, it is common for investors to use multiple brokers to trade in the same day, so netting transactions could generate a loss of real stock market activity. 
13. The threshold is defined for each calendar year. To not overburden the notation, we avoid indexing the threshold by year.

14. A directed network considers that $i j \neq j i$ for every $i j, j i \in$ $G_{t}$.

15. Every network characteristic (dimension) takes a value between -1 and 1 (i.e., $v_{t, d} \in[-1,1]$ for all $t$ and $d \in$ $[1,2, \ldots, D])$.

16. A complete network is a network where every possible link between each pair of nodes in the network exists. Because we use directed networks, the complete network is a network where every broker has a directed link to and from every other broker in the network.

17. To the extent that in some general equilibrium models price changes have a normative interpretation, one could extend the positive interpretation of such a correlation to a normative correlation. However, this is not our intent in this paper and, thus, the latter could be the subject of further research.

18. All explanatory variables are percentage changes of the financial variables.

19. Remember that the measure $k 1$ implies that when it increases in value, the network has changed more.

20. Autocorrelograms are available upon request.

21. This result should not be interpreted as returning to the original network. It only shows that the network has a tendency to reduce its structural change after two days of considerable structural movement.

22. Note that such shocks coincide in $60 \%$ of the cases with the shocks to IPSA.

23. They are available upon request.

\section{References}

[1] H. R. Stoll, "Chapter 9 Market microstructure," Handbook of the Economics of Finance, vol. 1, pp. 553-604, 2003.

[2] D. Easley and M. O’Hara, “Chapter 17 Microstructure and asset pricing," Handbook of the Economics of Finance, vol. 1, pp. 10211051, 2003.

[3] D. Vayanos and J. Wang, "Market Liquidity-Theory and Empirical Evidence *" Handbook of the Economics of Finance, vol. 2, pp. 1289-1361, 2013.

[4] A. G. Haldane, "Rethinking the financial network," In Fragile Stabilitätstabile Fragilität, pp. 243-278, 2013.

[5] Y. Bar-Yam and I. R. Epstein, "Response of complex networks to stimuli," Proceedings of the National Acadamy of Sciences of the United States of America, vol. 101, no. 13, pp. 4341-4345, 2004.

[6] D. Acemoglu, A. Ozdaglar, and A. Tahbaz-Salehi, "Systemic risk and stability in financial networks," American Economic Review, vol. 105, no. 2, pp. 564-608, 2015.

[7] N. Kiyotaki and J. Moore, "Credit cycles," Journal of Political Economy, vol. 105, no. 2, pp. 211-248, 1997.

[8] F. Allen and D. Gale, "Financial contagion," Journal of Political Economy, vol. 108, no. 1, pp. 1-33, 2000.
[9] X. Freixas, B. M. Parigi, and J.-C. Rochet, "Systemic risk, interbank relations, and liquidity provision by the Central Bank," Journal of Money, Credit and Banking, vol. 32, no. 4, pp. 611-638, 2000.

[10] S. Vivier-Lirimont, "Contagion in Interbank Debt Networks," Tech. Rep., Reims Management School and CES, Paris I Pantheon Sorbonne University, 2006.

[11] L. Blume, D. Easley, J. Kleinberg, R. Kleinberg, and É. Tardos, "Which networks are least susceptible to cascading failures?" in Proceedings of the 2011 IEEE 52nd Annual Symposium on Foundations of Computer Science, FOCS 2011, pp. 393-402, usa, October 2011.

[12] L. Blume, D. Easley, J. Kleinberg, R. Kleinberg, and E. Tardos, "Network formation in the presence of contagious risk," in Proceedings of the 12th ACM Conference on Electronic Commerce, EC'11, pp. 1-10, usa, June 2011.

[13] R. M. May, "Network structure and the biology of populations," Trends in Ecology \& Evolution, vol. 21, no. 7, pp. 394-399, 2006.

[14] M. Pröpper, I. Van Lelyveld, and R. Heijmans, "Towards a network description of interbank payment flows," DNB Working Paper, 2008.

[15] B. Porterie, A. Kaiss, J.-P. Clerc, L. Zekri, and N. Zekri, "Universal scaling in wildfire fractal propagation," Applied Physics Letters, vol. 93, no. 20, Article ID 204101, 2008.

[16] R. Albert, H. Jeong, and A.-L. Barabási, "Error and attack tolerance of complex networks," Nature, vol. 406, no. 6794, pp. 378$382,2000$.

[17] S. M. Guerra, T. C. Silva, B. M. Tabak, R. A. de Souza Penaloza, and R. C. de Castro Miranda, "Systemic risk measures," Physica A: Statistical Mechanics and its Applications, vol. 442, Article ID 16392, pp. 329-342, 2016.

[18] R. M. May, S. A. Levin, and G. Sugihara, "News \& views ecology for bankers," Nature, vol. 451, no. 7181, pp. 893-895, 2008.

[19] A. Sensoy and B. M. Tabak, "Dynamic spanning trees in stock market networks: the case of Asia-Pacific", Physica A: Statistical Mechanics and its Applications, vol. 414, pp. 387-402, 2014.

[20] R. Kinney, P. Crucitti, R. Albert, and V. Latora, "Modeling cascading failures in the North American power grid," The European Physical Journal B, vol. 46, no. 1, pp. 101-107, 2005.

[21] H. R. Stoll and R. E. Whaley, "Stock Market Structure and Volatility," Review of Financial Studies, vol. 3, no. 1, pp. 37-71, 1990.

[22] M. J. Brennan and A. Subrahmanyam, "Market microstructure and asset pricing: on the compensation for illiquidity in stock returns," Journal of Financial Economics, vol. 41, no. 3, pp. 441464, 1996.

[23] M. J. Brennan, T. Chordia, and A. Subrahmanyam, "Alternative factor specifications, security characteristics, and the crosssection of expected stock returns," Journal of Financial Economics, vol. 49, no. 3, pp. 345-373, 1998.

[24] M. Fratzscher, M. Lo Duca, and R. Straub, "On the international spillovers of US quantitative easing," The Economic Journal, 2016.

[25] G. B. Estrada, D. Park, and A. Ramayandi, "Taper Tantrum and Emerging Equity Market Slumps," Emerging Markets Finance and Trade, vol. 52, no. 5, pp. 1060-1071, 2016.

[26] R. Lavigne, S. Sarker, and G. Vasishtha, "Spillover effects of quantitative easing on emerging-market economies," Bank of Canada Review, vol Autumm, pp. 23-33, 2014.

[27] Q. Chen, A. Filardo, D. He, and D. Zhu, "International spillovers of central bank balance sheet policies," in BIS Papers, vol. 66, pp. 1-49, 2012. 
[28] L. Jaramillo and A. Weber, "Bond yields in emerging economies: It matters what state you are in," Emerging Markets Review, vol. 17, pp. 169-185, 2013.

[29] M. Pedersen, "The impact of commodity price shocks in a major producing economy. the case of copper and chile," Banco Central de Chile, 2015.

[30] L. Brandao-Marques, "Stock Market Liquidity in Chile," IMF Working Papers, vol. 16, no. 223, p. 1, 2016.

[31] J. Lavin and N. Magner, "Reversing the question: on what does the turnover of mutual funds depend? evidence from equity mutual funds in chile," Emerging Markets Finance \& Trade, vol. 50, no. 5, pp. 110-129, 2014.

[32] S. Huddart, M. Lang, and M. H. Yetman, "Volume and price patterns around a stock's 52-week highs and lows: Theory and evidence," Management Science, vol. 55, no. 1, pp. 16-31, 2009.

[33] T. U. Kuzubaş, I. Ömercikoǧlu, and B. Saltoǧlu, "Network centrality measures and systemic risk: An application to the Turkish financial crisis," Physica A: Statistical Mechanics and its Applications, vol. 405, pp. 203-215, 2014.

[34] S. Martínez-Jaramillo, B. Alexandra-Kabadjova, B. BravoBenítez, and J. Solózano-Margain, "An empirical study of the mexican banking system's network and its implications for systemic risk," Journal of Economic Dynamics \& Control, vol. 40, pp. 242-265, 2014. 


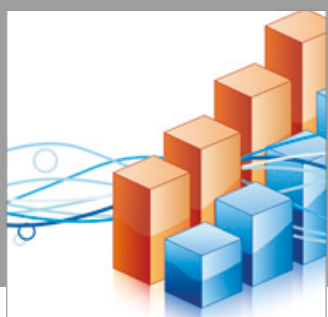

Advances in

Operations Research

vatersals

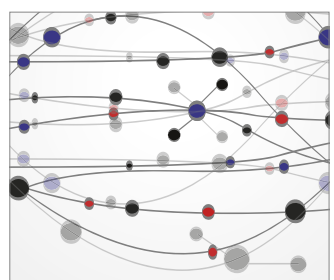

\section{The Scientific} World Journal
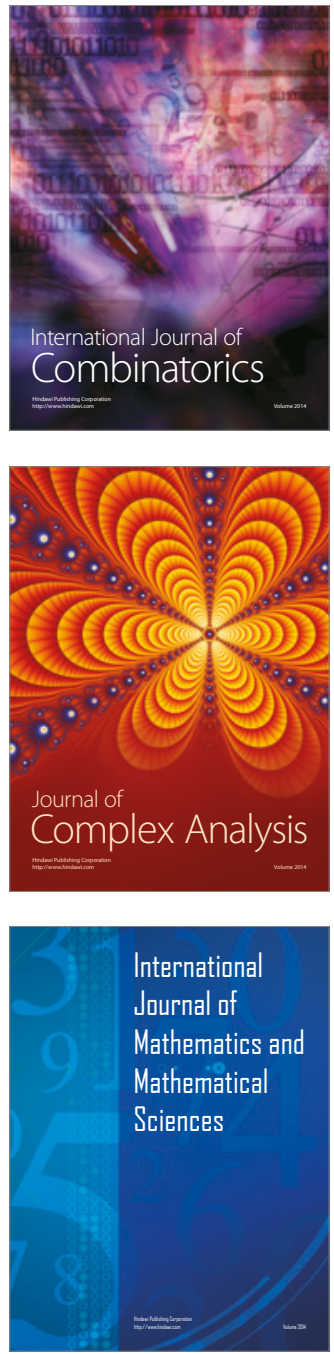
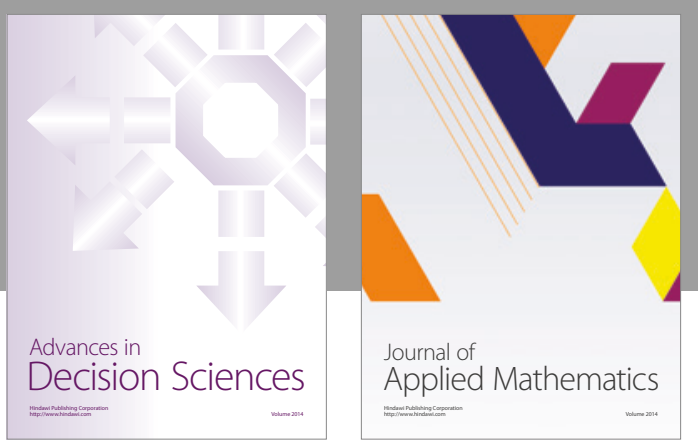

Algebra

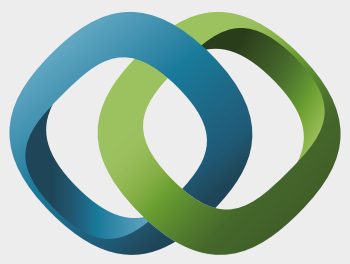

\section{Hindawi}

Submit your manuscripts at

https://www.hindawi.com
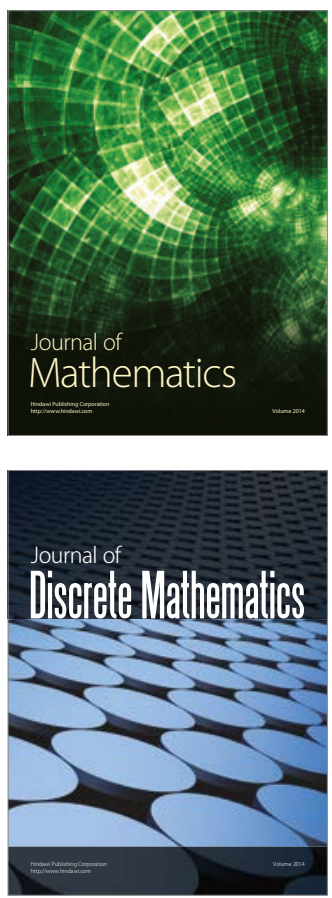

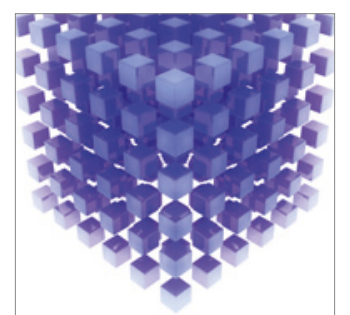

Mathematical Problems in Engineering
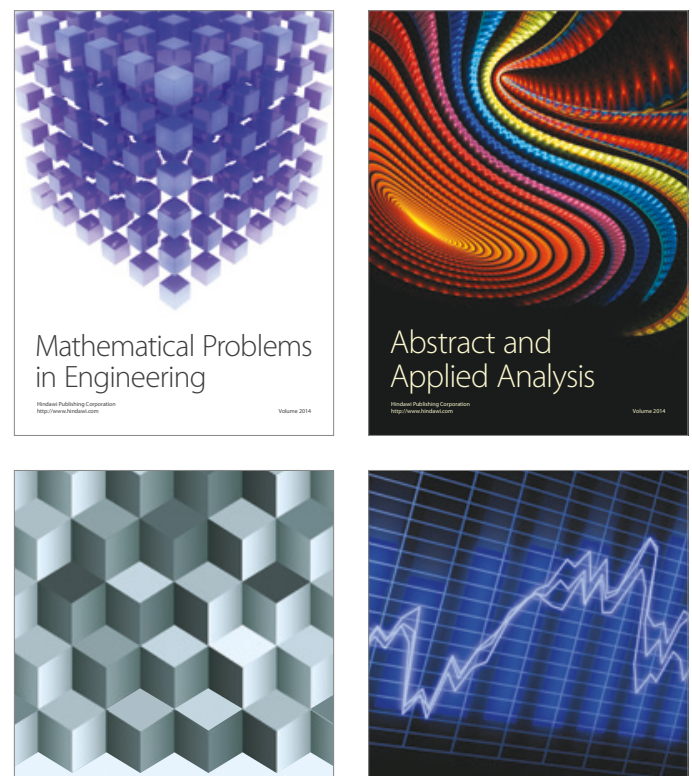

Journal of

Function Spaces

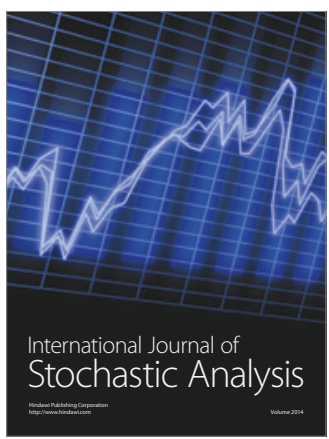

Probability and Statistics
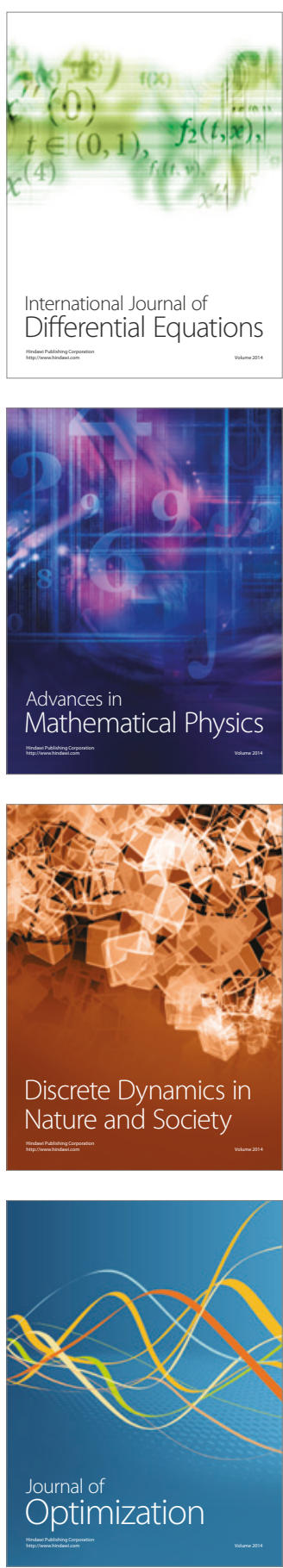